\title{
Innovations in cardiovascular surgical technique: Separating the wheat from the chaff
}

\author{
Anelechi C. Anyanwu, MD, and Martin T. Yates, MD
}

\author{
From the Department of Cardiovascular Surgery, Mount Sinai Medical Center, New York, NY. \\ Disclosures: Authors have nothing to disclose with regard to commercial support. \\ Received for publication March 1, 2018; accepted for publication March 6, 2018; available ahead of print April \\ $12,2018$. \\ Address for reprints: Anelechi C. Anyanwu, MD, Department of Cardiovascular Surgery, Mount Sinai Medical \\ Center, 1190 Fifth Ave, Box 1028, New York, NY, 10029 (E-mail: Anelechi.anyanwu@mountsinai.org). \\ J Thorac Cardiovasc Surg 2018;156:647-8 \\ $0022-5223 / \$ 36.00$ \\ Copyright (C) 2018 by The American Association for Thoracic Surgery \\ https://doi.org/10.1016/j.jtcvs.2018.03.019
}

In this issue of the Journal, Eishi and colleagues ${ }^{1}$ describe a novel repair technique to treat severe secondary tricuspid valve regurgitation. The procedure was performed on 7 patients from 2015 through 2016, with good early outcomes. The technique attempts to improve the durability of tricuspid valve repair by reducing papillary muscle displacement.

Surgeons are innovators, and we all strive to develop and modify surgical techniques. Our innovations are typically popularized through case reports in journals and video presentations at meetings, often before the technique has undergone formal evaluation. What should the reader of the Journal do after reading a report of a new technique? Should we all go to the operating room tomorrow and perform the new spiral technique of Eishi and colleagues ${ }^{1}$ for repair of the tricuspid valve? If not, how do we further explore the concept introduced by the report? This is a conundrum faced by the readers of any case report on a new technique. Invariably, case reports of novel techniques do not show whether a technique is effective or beneficial. When the effects of a new technique are immediate or lifesaving (such as an approach for dealing with a lethal intraoperative problem), one may not need evidence of effectiveness; it is reasonable for a reader to try such approach without further data. For valve surgery, however, the effectiveness and safety of a treatment technique cannot be established until a reasonably sized cohort of patients has been followed up for at least a few years. Although 1-year outcomes of a small series of initial patients may be helpful in highlighting some procedures that clearly do not work (because of a high rate of early failure), they are incapable of ascertaining whether a valve procedure truly works and is durable. Indeed, a review of the literature shows an abundance of descriptions of surgical techniques that are no longer used, abandoned even by the original proponents. Some new techniques have resulted in harm to patients in a phase of early enthusiastic adoption, whereas others were later found to be ineffective when subjected to follow-up or formal study. There are many other undertaken.

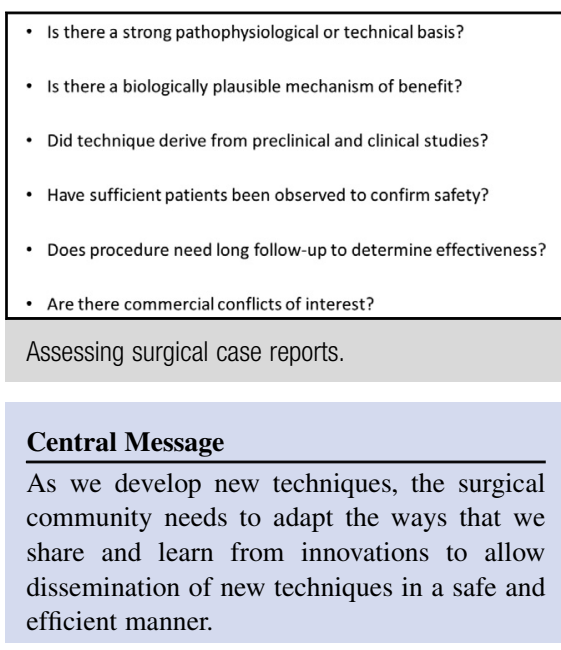

See Article page 649.

procedures, however, that started as initial case reports and are now used extensively. Historically, peer review and publication delay in print journals limited rapid dissemination of new techniques, so by the time new techniques were in print, the proponents had a clearer perception of its application, effectiveness, and utility. In the current era of electronic communications, electronic journal publications, and accelerated submission to publication times, however, information is shared more rapidly. Although this speed may have positive effect, there is also greater likelihood that readers of journals will be exposed to new techniques well before reasonable evaluation has been

How do surgeons tell the wheat from the chaff? Which procedures should we adopt on the basis of a case report, which should we not adopt, and which should we defer until there are further data? Ideally, we all want a prospective study or randomized trial, but in reality, this is not practical for most surgery that we do. A prerequisite for adopting any new technique is that there should be sufficient underlying pathophysiologic or technical basis, and also a biologically plausibility mechanism for its effectiveness. Readers should look at the track record of the report's authors and their persistence with the innovation. The surgeon innovator who flirts from one idea to another is unlikely to spend enough time on a particular technique to have researched its basis and tested its hypothesis. A technique that has evolved with time through laboratory and clinical studies 
is likely to be more tested and thought through than one that has been conceptualized de novo and rapidly published. The reader also has to consider the time span required to separate success from failure for a given procedure. For valve repair, this is typically a few years, so there must be strong basis to believe that an untested new repair procedure would be successful before adoption. Reports of early echocardiographic success are not necessarily predictive of late success. Case reports that showcase the use of a commercial product are often inherently biased, because of conflicts of interest, and they thus require a much higher level of scrutiny.

Journals and meetings should promote open access discussion and feedback. Contingent on publication of case reports could be a commitment by the authors to provide an electronically appended update after a designated period, to tell readers whether their initial views of the procedure still hold. When such innovations are adopted at other centers, their experiences could be shared by electronic linkage with the original description. Finally, information on new techniques must be easily accessible and searchable to prevent duplication of innovations and, more importantly, duplication of known harmful techniques. It is essential that we, as cardiac surgeons, continue to develop our surgical techniques for the benefit of our increasingly complex patient population, but we need to innovate and adapt the ways that we share and learn from others' experiences to allow progress and dissemination of new techniques in a safe and efficient manner. So, should we all go to the operating room tomorrow and perform the spiral technique of Eishi and colleagues ${ }^{1}$ for repair of the tricuspid valve? Probably not. The technique is certainly innovative, and it is to be hoped that it has promise. With very limited outcome data, however, it is not ready for widespread application outside a research study. Time will tell how the concept will evolve.

\section{Reference}

1. Eishi K, Miura T, Matsumaru I, Tanigawa K, Obase K. Spiral suspension, a novel repair technique for severe functional tricuspid regurgitation. J Thorac Cardiovasc Surg. 2018;156:649-52. 